\title{
Draft Aphaenogaster genomes expand our view of ant genome size variation across climate gradients
}

\author{
Matthew K Lau Corresp., 1 , Aaron M Ellison ${ }^{1}$, Andrew Nguyen ${ }^{2,3}$, Clint Penick ${ }^{4}$, Bernice DeMarco \\ Gotelli $^{3}$, Nathan J Sanders ${ }^{6}$, Robert R Dunn ${ }^{7}$, Sara Helms Cahan ${ }^{3}$ \\ 1 Harvard Forest, Harvard University, Petersham, MA, United States \\ 2 Department of Entomology and Nematology, University of Florida, Gainesville, FL, United States \\ 3 Department of Biology, University of Vermont, Burlington, VT, United States \\ 4 The Biomimicry Center, Arizona State University, Tempe, AZ, United States \\ 5 Smithsonian Institution, Washington, DC, USA \\ 6 Environmental Program, Rubenstein School of Environment and Natural Resources, University of Vermont, Burlington, VT, United States \\ 7 Department of Applied Ecology, North Carolina State University, Raleigh, NC, United States \\ Corresponding Author: Matthew K Lau \\ Email address: matthewklau@fas.harvard.edu
}

Given the abundance, broad distribution, and diversity of roles that ants play in many ecosystems, they are an ideal group to serve as ecosystem indicators of climatic change. At present, only a few whole-genome sequences of ants are available (19 of $>16,000$ species), mostly from tropical and sub-tropical species. To address this limited sampling, we sequenced genomes of temperate-latitude species from the genus Aphaenogaster, a genus with important seed dispersers. In total, we sampled seven colonies of six species: $A$. ashmeadi, $A$. floridana, $A$. fulva, $A$. miamiana, $A$. picea, and $A$. rudis. The geographic ranges of these species collectively span eastern North America from southern Florida to southern Canada, which encompasses a latitudinal gradient in which many climatic variables are changing rapidly. For the six genomes, we assembled an average of 271,039 contigs into 47,337 scaffolds. The Aphaenogaster genomes displayed high levels of completeness with $96.1 \%$ and $97.6 \%$ of Hymenoptera BUSCOs completely represented, relative to currently sequenced ant genomes which ranged from $88.2 \%$ to $98.5 \%$. Additionally, the mean genome size was $370.5 \mathrm{Mb}$, ranging from 310.3 to 429.7 , which is comparable to that of other sequenced ant genomes (212.8 to $396.0 \mathrm{Mb}$ ) and flow cytometry estimates (210.7 to $690.4 \mathrm{Mb}$ ). In an analysis of currently sequenced ant genomes and the new Aphaenogaster sequences, we found that after controlling for both spatial autocorrelation and phylogenetics ant genome size was marginally correlated with sample site climate similarity. Of all examined climate variables, minimum temperature and annual precipitation had the strongest correlations with genome size, with ants from locations with colder minimum temperatures and higher levels of precipitaion having larger genomes. These results suggest that climate extremes could be a selective force 
acting on ant genomes and point to the need for more extensive sequencing of ant genomes. 


\title{
Draft Aphaenogaster genomes expand our view of ant genome size variation across climate gradients
}

\author{
Matthew K. Lau ${ }^{1}$, Aaron M. Ellison ${ }^{1}$, Andrew D. Nguyen ${ }^{2,3}$, Clint Penick $^{4,5}$, \\ Bernice DeMarco ${ }^{6}$, Nicholas J. Gotelli ${ }^{2}$, Nathan J. Sanders ${ }^{7}$, Robert R. \\ Dunn $^{4}$, and Sara Helms Cahan ${ }^{2}$ \\ ${ }^{1}$ Harvard Forest, Harvard University, Petersham, MA, USA \\ ${ }^{2}$ Department of Biology, University of Vermont, Burlington, VT, USA \\ ${ }^{3}$ Department of Entomology and Nematology, University of Florida, Gainesville, FL, \\ USA \\ ${ }^{4}$ Department of Applied Ecology, North Carolina State University, Raleigh, NC, USA \\ ${ }^{5}$ The Biomimicry Center, Arizona State University, Tempe, AZ, USA \\ ${ }^{6}$ Smithsonian Institution, Washington, DC, USA \\ ${ }^{7}$ Environmental Program, Rubenstein School of Environment and Natural Resources, \\ University of Vermont, Burlington, VT, USA \\ Corresponding author: \\ Matthew K. Lau \\ Email address: matthewklau@fas.harvard.edu
}

\begin{abstract}
Given the abundance, broad distribution, and diversity of roles that ants play in many ecosystems, they are an ideal group to serve as ecosystem indicators of climatic change. At present, only a few whole-genome sequences of ants are available (19 of $>16,000$ species), mostly from tropical and sub-tropical species. To address this limited sampling, we sequenced genomes of temperate-latitude species from the genus Aphaenogaster, a genus with important seed dispersers. In total, we sampled seven colonies of six species: $A$. ashmeadi, $A$. floridana, $A$. fulva, $A$. miamiana, $A$. picea, and $A$. rudis. The geographic ranges of these species collectively span eastern North America from southern Florida to southern Canada, which encompasses a latitudinal gradient in which many climatic variables are changing rapidly. For the six genomes, we assembled an average of 271,039 contigs into 47,337 scaffolds. The Aphaenogaster genomes displayed high levels of completeness with $96.1 \%$ and $97.6 \%$ of Hymenoptera BUSCOs completely represented, relative to currently sequenced ant genomes which ranged from $88.2 \%$ to $98.5 \%$. Additionally, the mean genome size was $370.5 \mathrm{Mb}$, ranging from 310.3 to 429.7 , which is comparable to that of other sequenced ant genomes (212.8 to $396.0 \mathrm{Mb}$ ) and flow cytometry estimates (210.7 to $690.4 \mathrm{Mb}$ ). In an analysis of currently sequenced ant genomes and the new Aphaenogaster sequences, we found that after controlling for both spatial autocorrelation and phylogenetics ant genome size was marginally correlated with sample site climate similarity. Of all examined climate variables, minimum temperature and annual precipitation had the strongest correlations with genome size, with ants from locations with colder minimum temperatures and higher levels of precipitaion having larger genomes. These results suggest that climate extremes could be a selective force acting on ant genomes and point to the need for more extensive sequencing of ant genomes.
\end{abstract}

\section{INTRODUCTION}

Understanding how terrestrial ecosystems will respond to ongoing shifts in climatic variables, such as temperature and precipitation, will improve our ability to manage communities and mitigate impacts of climatic change. The mean global temperature is currently on track to meet or exceed that predicted by 
the most extreme forecasting models (Brown and Caldeira, 2017). Climatic change is also pushing local conditions outside the boundaries of historic ranges, potentially leading to combinations of species or entire ecosystems that have no contemporary analogs (Burrows et al., 2014). As climate-driven impacts on evolutionary responses are likely to occur over contemporary time scales, with the potential for ecological and evolutionary dynamics to affect communities and ecosystem processes (Rowntree et al., 2011; Des Roches et al., 2017), there is a need for a comprehensive study of the genetic basis of species' responses to climate (Parmesan, 2006).

The biodiversity of most terrestrial systems is great enough to be intractable to study in its entirety. To deal with this, researchers often study 'indicator' species whose responses to environmental change are broadly representative of a much wider range of taxa (Siddig et al., 2016). Ants (Formicidae), in particular, are widely used as indicator taxa (Agosti et al., 2000) as they play key roles in community dynamics and ecosystem processes, including key interactions, such as seed dispersal and the movement of soil via colony construction (Del Toro et al., 2012). Ants also are responsive to changes in temperature and other climatic variables via individual responses, changes in colony structure and community assembly (Kaspari et al., 2015; Spicer et al., 2017; Diamond et al., 2017; Diamond and Chick, 2018).

Multiple studies support the perspective that a more complete knowledge of ant genetics will increase our understanding of ant responses to environmental change (Diamond et al., 2012; Nygaard and Wurm, 2015; Stanton-Geddes et al., 2016; Boomsma et al., 2017; Penick et al., 2017). Studies of ant genomes have shed light on the evolution and social organization of ants (Libbrecht et al., 2013). One promising avenue is the possibility of genome size as an adaptive trait in ants. Recent observational studies have reported biogeographic patterns in genome size in arthropod taxa, e.g. Crustacea (Hultgren et al., 2018), and patterns in insect genomes suggest that climate may constrain genome size with cold temperatures possibly selecting for larger genome sizes (Mousseau, 1997; Petrov, 2001; Alfsnes et al., 2017). Specific to ants, previous research into genome size variation using flow cytometry found that ants have small genomes relative to other insect taxa and that their genomes display large variation across subfamilies with patterns indicative of both gradual and rapid evolution in genome size (Tsutsui et al., 2008).

At present relatively few ant species have been sequenced - 20 in total, of which 19 are currently available in the NCBI Genome Database (accessed 18 Dec 2018, see Supplementary Materials Table 1). Of these, most are from tropical and subtropical assemblages (Fig 1), and all but five represent unique genera (the exceptions being two species of Atta and three of Trachymyrmex). No species of Aphaenogaster, which are abundant ants that play key roles in the dispersal of understory plant species in North America and temperate Asia, have yet been sequenced. Previous studies have also shown that Aphaenogaster species' ecological and physiological responses to climatic change appear to depend both 
on species identity and on the geographic region in which climatic change occurs (Warren and Chick, 2013; Stanton-Geddes et al., 2016).

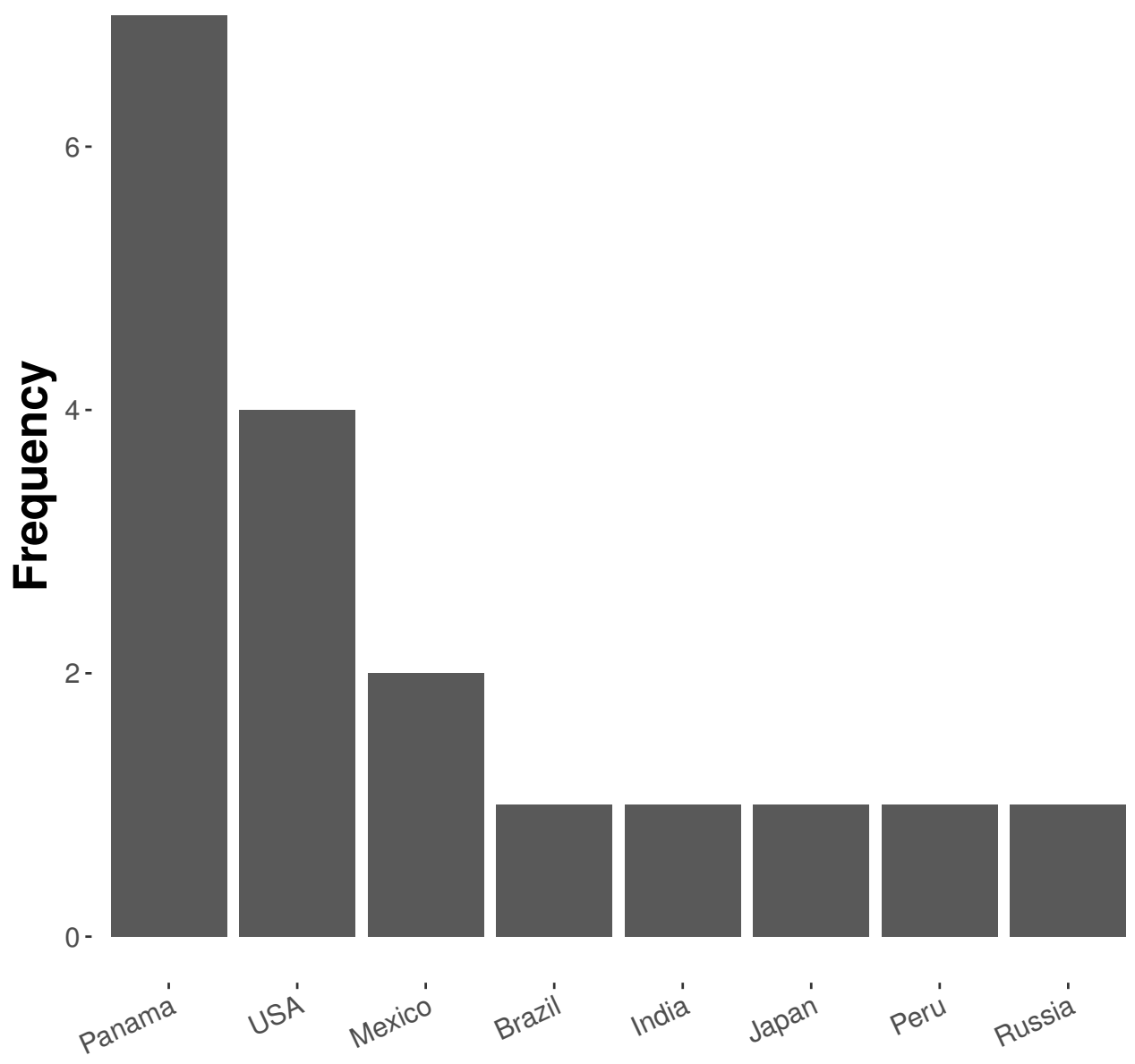

Figure 1. Number of ant (Formicidae) whole-genome sequences available in NCBI by country (accessed August 2018).

To increase the number of genomes of temperate-zone ant species, we sequenced the genomes of Aphaenogaster species. We conducted whole genome sequencing for six species: A. ashmeadi, A. floridana, A. fulva, A. miamiana, A. picea and A. rudis. These species were collected from across a broad biogeographic gradient spanning 10 degrees of longitude and 12 degrees of latitude. We also conducted an initial exploration of biogeographic patterns in ant genome sequences, focusing on genome size. To do this we analyzed the newly collected Aphaenogaster sequences together with all publicly available ant whole genome sequences. We present the newly sequenced Aphaenogaster genomes and investigate biogeographic (i.e. location and climate) related patterns of ant genomes using all currently sequenced ant genomes. 


\section{MATERIALS \& METHODS}

\section{Sampling and Whole-genome Sequencing and Assembly}

Entire colonies of the six Aphaenogaster species were collected by A. Nguyen and C. Penick from field sites in eastern North America (Fig 2 and Table 1). Ants were identified to species and voucher specimens have been deposited at the Museum of Comparative Zoology, Harvard University. Individuals from each colony were isolated from nest material and debris, weighed, placed in $50 \mathrm{ml}$ Falcon centrifuge tubes, and immediately flash frozen in a $-80^{\circ} \mathrm{C}$ freezer. Colony weights were: $794 \mathrm{mg}$ (A. ashmeadi), $652 \mathrm{mg}($ A. floridana), $520 \mathrm{mg}$ (A. fulva), $749 \mathrm{mg}$ (A. picea), $862 \mathrm{mg}$ (A. miamiana), $280 \mathrm{mg}$ (A. rudis 1) and $236 \mathrm{mg}$ (A. rudis 2).
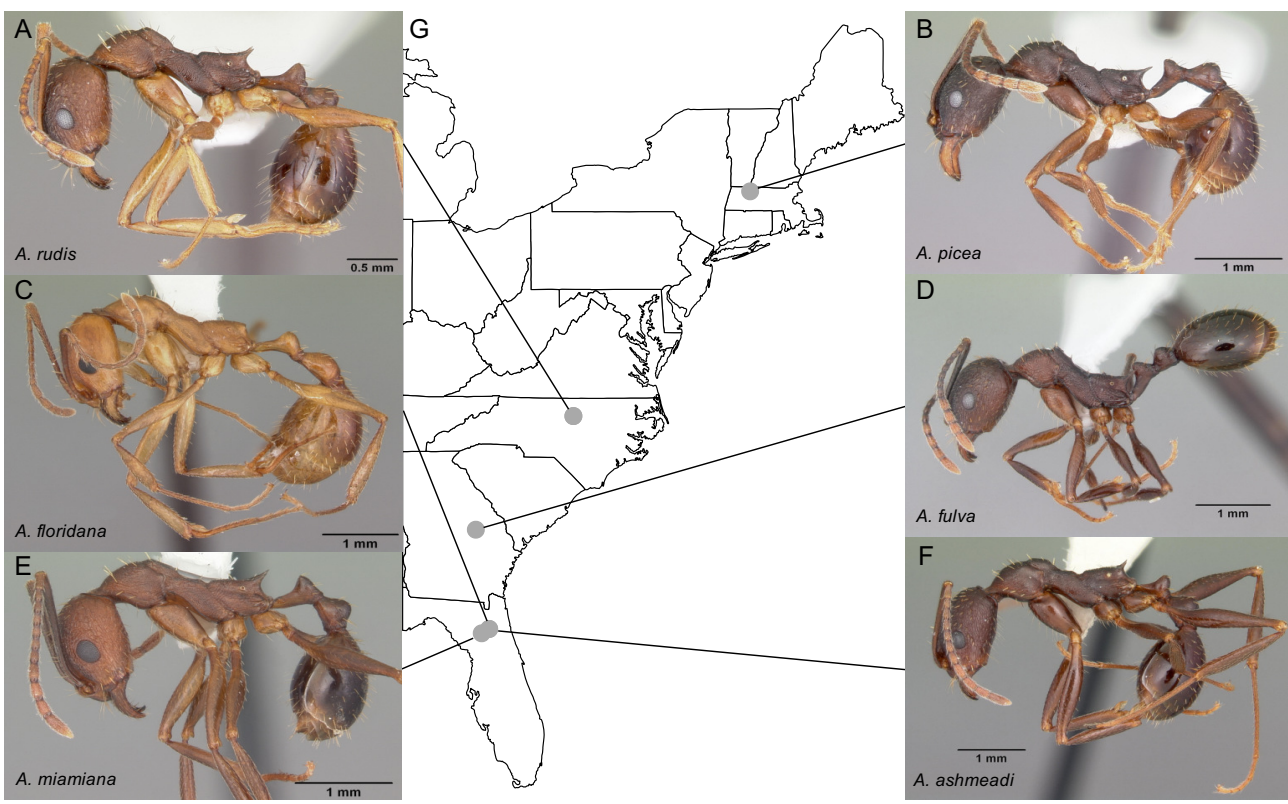

Figure 2. We sampled seven colonies representing six species of Aphaenogaster, including A) A. rudis, B) A. picea, C) A. floridana, D) A. fulva, E) A. miamiana and F) A. ashmeadi from G) sampling locations across eastern North America (see Table 1). All photos by April Noble (available from http://www.antweb.org).

\begin{tabular}{rrrrrr}
\hline & Lat & Lon & Tmin (C) & Tmax (C) & Precip (mm) \\
\hline Aphaenogaster ashmeadi & 29.79 & -82.03 & 5.80 & 32.70 & 1314 \\
Aphaenogaster floridana & 29.79 & -82.03 & 5.80 & 32.70 & 1314 \\
Aphaenogaster fulva & 32.69 & -82.51 & 1.30 & 33.30 & 1155 \\
Aphaenogaster miamiana & 29.66 & -82.30 & 5.90 & 32.80 & 1322 \\
Aphaenogaster picea & 42.60 & -72.58 & -12.40 & 28.30 & 1122 \\
Aphaenogaster rudis1 & 36.02 & -78.98 & -2.70 & 31.50 & 1164 \\
Aphaenogaster rudis2 & 36.02 & -78.98 & -2.70 & 31.50 & 1164 \\
\hline
\end{tabular}

Table 1. Climate variables for colony sample sites. Climate are 30 year normal values (1970-2000) for minimum temperature of the coldest month (Tmin), maximum temperature of the warmest month (Tmax) and total precipitation (Precip) from the WorldClim database accessed on 08 August 2018. 
Whole colony DNA was used to have sufficient concentrations for sequencing. DNA was then extracted from each colony using methods developed previously for genomic sequencing of whole colonies of colonial mosquitos (Anopheles spp.) (Neafsey et al., 2010) and sequenced using an Illumina HiSeq 2500 at the Broad Institute (Cambridge, MA, USA). A combination of fragment and jump sequences were used to generate higher quality, long sequence reads.

Raw sequences were processed to remove chimeric and contaminant sequences, screened for contaminants by BLAST searches (using blastn) to identify sequences with likely matches to non-target species (primarily Wolbachia and Mycoplasma), and assembled using ALLPATHS-LG (version r48559) (Gnerre et al., 2011). Additional assembly processing using PILON (version 1.13) (Walker et al., 2014) was applied to reduce base-call errors and gaps in coverage. On average, across all seven genomes, PILON reduced coverage gaps by $3.1 \%$ or $3.9 \mathrm{Mb}$. GAEMR (http://www.broadinstitute.org/software/gaemr/) software produced summary statistics of the final assembled genomes. Once assembled, repeat regions in the Aphaenogaster genomes were detected and masked using Repeatmasker (version 4.0.5 Institute for Systems Biology). Genome completeness was assessed for all ant genome genome assemblies using BUSCO version 3.0.2 (Waterhouse et al., 2018) with the Hymenoptera BUSCO lineage (ODB9 from 13 February 2017) with the honey bee starting genome and HMMER version 3.1b1, BLAST+ version 2.2.31 and AUGUSTUS version 3.0.3 dependencies. For each genome we ran BUSCO on the final contaminant removed, repeat-masked Aphaenogaster assemblies and the most recent published assembly for the NCBI published genomes.

\section{Analysis of Genomes along Climate Gradients}

After masking repeat regions, we applied MASH distance (Ondov et al., 2016) to measure pairwise dissimilarity of genomic sequences. The MASH method extends a data compression and dimensionalityreduction algorithm to generate estimates of sequence similarity with low computational overhead. Briefly, the pairs of genomic sequences were pre-processed into sets of k-mers of size 21 with the size of the non-redundant hashes retained set to 1,000 . These settings have been demonstrated to provide good representation of genomic similarity with minimal computational costs (Ondov et al., 2016). These sets were then used to estimate the Jaccard similarity coefficient (the ratio of shared k-mers to total k-mers) of subsampled k-mer pairs of genomes. This unbiased estimate of the Jaccard similarity $(J)$ was then used to calculate the dissimilarity of the two genomes $(D)$ as $D=1-J$. All Jaccard similarity estimates had $p$-values less than $10^{-14}$, which is below the recommended $10^{-3}$ probability of observing values of $J$ due to chance.

We used multivariate correlation analyses to examine biogeographic patterns of ant genomes. Mantel tests of multivariate correlation of distance matrices were used to examine correlations among ant genomes 
and climate variables. Specifically, we used directional $\left(\mathrm{H}_{\circ}\right.$ : Mantel $\left.\mathrm{r} \leq 0\right)$ partial mantel tests, which calculate the correlation between two distance matrices while controlling for the covariance with other matrices (Goslee and Urban, 2007). First, we examined the correlations between genomic similarity (MASH distance), whole-genome size similarity (Euclidean distance of assembly size in total base pairs) and climate variables (also using Euclidean distance). Via partial Mantel tests, we were able to isolate the correlation between genome size and climate by controlling for spatial autocorrelation and potential phylogenetic patterns by including geodesic and MASH distances as terms.

We obtained previously sequenced ant whole genome and climate data from a publicly available databases. Whole genome sequences for ants were obtained from the NCBI Genome database (accessed August 2018, see Supplementary Materials Table 1). Climatic variables for each sampling location (see Table 2) were obtained from the WorldClim database (version 2.0) at a 2.5 arc minute spatial resolution from the years 1970 to 2000 (Fick and Hijmans, 2017). Although used in the previous analyses of ant genomes, two species, (Wasmannia auropunctata and Monomorium pharaonis), which did not have published location information, were excluded from biogeographic analyses.

Using a permutational multivariate analysis of variance (PerMANOVA) procedure, we parsed the individual variables that were correlated with both genome size and MASH similarity. PerMANOVA is a flexible multivariate analog of ANOVA that permits the use of a wider set of similarity metrics to be used for the response matrix (Anderson, 2001), such as the MASH distance. We ran a total of 10,000 permutations of the original distance matrices for each statistical permutation procedure. We chose a subset of all possible climate variables available via WorldClim for this analysis. A visual inspection of the sampled climate variable correlations indicated that the primary climate variables, mean annual temperature (MAT), minimum temperature of the coldest month (Tmin), maximum temperature of the hottest month (Tmax), annual precipitation (PA) and precipitation seasonality (PS), represented the majority of climate variation (Fig 3). Based on this, we only included these variables, along with latitude and longitude coordinates, as factors in the PerMANOVAs.

It is important to note that we are using assembly length as an indicator of genome size. As genome size estimates are generally used to set assembly size targets for whole genome sequencing efforts (Hare and Johnston, 2011), we expect there to be a high degree of correlation between assembly size and genome size. Also, as a test of the potential relationship between assembly size and true genome size, we examined the correlation between the average assembly sizes of ant genera that overlapped with flow cytometry estimates of those published in Tsutsui et al. (2008). We applied leave-one-out outlier detection (Cook and Weisberg, 1982) to least squares regression analysis examining the predictive potential of assembly length and flow cytometry size estimates at the genus level and found one strong outlier (Supplementarty 
Materials Fig 1), Dinoponera quadriceps, whose assembly size was less than half the flow cytometry estimate (259.7 Mb vs. 554.7 Mb). After removing this species from the regression analysis we found a strong, significant relationship between assembly length and genome size $\left(\mathrm{R}^{2}=0.76, \mathrm{~F}_{1,5}=15.99\right.$, $p$-value $=0.010)$, which supports the use of assembly length as an indicator of genome size. Based on this, we did not include D. quadriceps in any of the analyses examining patterns of assembly length.

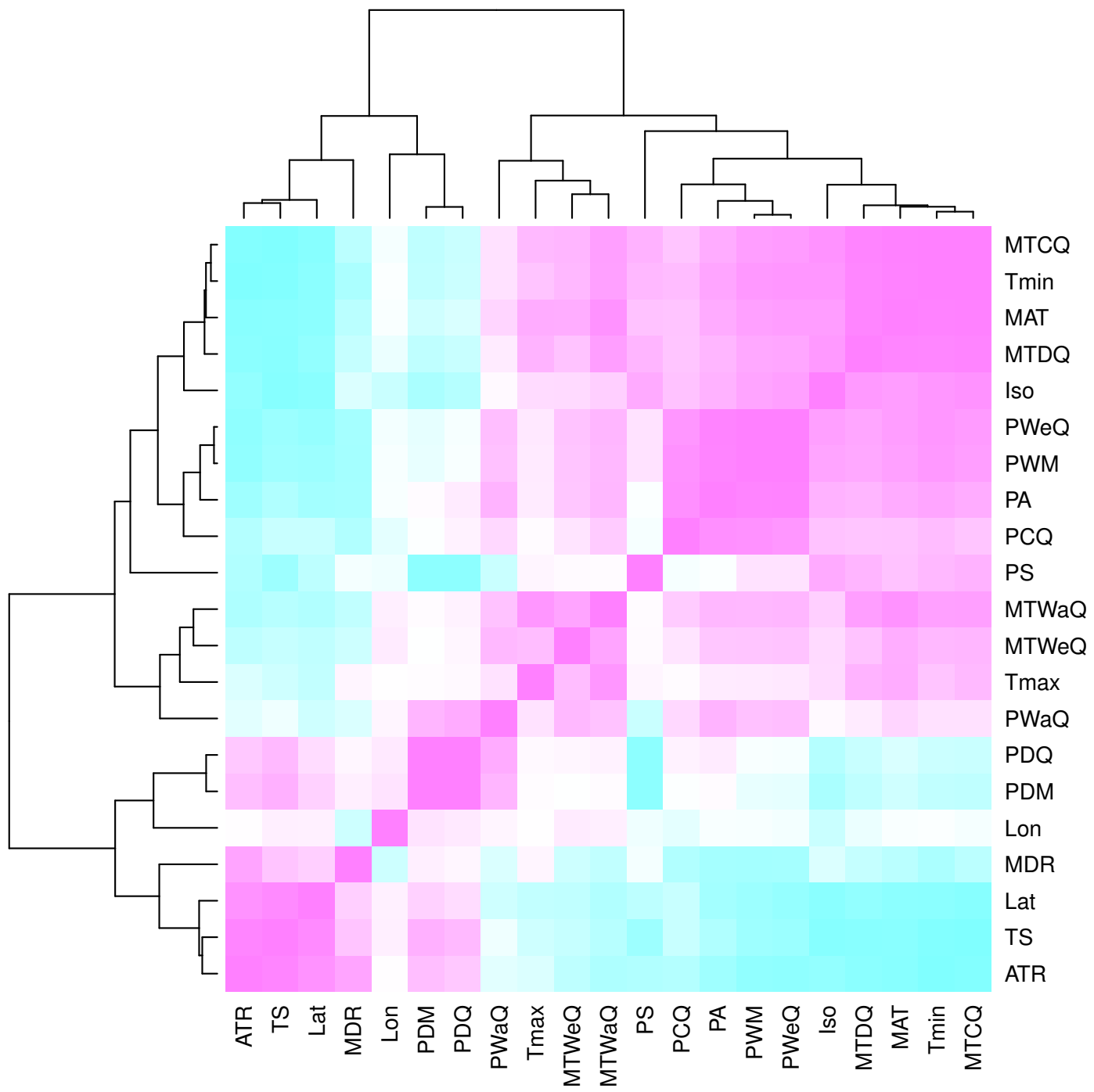

Figure 3. Heatmap of Pearson correlations among climate variables. Cells in the heatmap are colored by the correlation between the two variables that intersect at that location ranging from blue $=-1$ to white $=0$ to pink $=1$. The variables are arrayed by hierarchical clustering of the correlations, as shown by the dendrograms on the top and left side. For variable descriptions see Table 2.

\section{Data, Computation and Statistics}

The raw and assembled genome sequences are currently archived at Harvard Forest (Petersham, MA, USA) and in NCBI's genome database (Genome Accessions NJRK00000000-NJRQ00000000 and 
BioSample Accessions SAMN06892346-SAMN06892352). Genomic distance (MASH) computations were run on the Odyssey cluster supported by the FAS Division of Science, Research Computing Group at Harvard University. All analyses were conducted in $\mathbf{R}$ (R Core Team, 2017). Analytical scripts for the project have been versioned and archived (DOI: 10.5281/zenodo.1341982) and are available online at https://zenodo.org/record/1341982. We used the vegan (Oksanen et al., 2016) and ecodist (Goslee and Urban, 2007) packages in $\mathrm{R}$ for multivariate analyses.

\section{RESULTS}

\section{Genome Quality and Composition}

DNA extractions yielded substantial amounts of high quality DNA with concentrations and quality scores ranging from 3.45-5.39 $\mathrm{ng} \mu \mathrm{L}^{-1}$ and $4.05-4.27 \mathrm{ng} \mu \mathrm{L}^{-1}$, respectively. All genome assemblies displayed good coverage, with an average of $70 \%$ across all genomes (Table 3). Across all species, the length of the shortest contig at $50 \%$ of the genome (i.e. N50) was 18,864 bases; average assembly GC content was $38.18 \%$; and average genome size was $370.45 \mathrm{Mb}$. Using GAEMR's BLAST feature to conduct a search of the contigs against the NCBI's nucleotide sequence database, we discovered that $38.98 \%$ and $22.04 \%$ of the top hits were "ant" and Aphaenogaster, respectively. Using the Hymenoptera BUSCO set, the Aphaenogaster genomes displayed a high degree of completeness. Between 96.1\% and 97.6\% with an average of $97.0 \% \pm 0.2$ (S.E.) of Hymenoptera BUSCOs were completely represented. The Aphaenogaster genomes were among the more complete genomes, relative to the other sequenced ant genomes from NCBI, which ranged from $88.2 \%$ to $98.5 \%$ complete Hymenoptera BUSCOs with a an average of $96.3 \% \pm 0.5$ (S.E.) (Fig 4 A). Also, the sizes of the Aphaenogaster genomes were within the range of other ant genomes based on size from both flow cytometry (Tsutsui et al., 2008) and the previously sequenced ant genomes available in NCBI (Fig 4 B).

Using the MASH genomic distances, we observed patterns of genomic similarity that were in line with expectations of ant relatedness. Sequences formed groups that corresponded with subfamilies (Fig 5). Aphaenogaster clustered with other genera from the Myrmicinae and, in general, subfamily level clustering tended to follow previously observed patterns of subfamily relatedness (Bolton, 2006; Moreau, 2006; Ward, 2014). The Aphaenogaster sequences formed a single cluster containing only Aphaenogaster species and displayed intra-generic levels of genomic variance comparable to other genera s(e.g., Trachymyrmex spp.). The separation of the two A. rudis species was initially surprising, as these two samples were collected at the same site (Duke Forest, NC USA) and were identified as the same species based on their morphological characteristics (Ellison, 2012; DeMarco and Cognato, 2016). However, two recent studies of targeted gene regions have demonstrated the polyphyletic nature of Aphaenogaster rudis. 


\begin{tabular}{rr}
\hline WorldClim Variable & BIO Number \\
\hline Annual Mean Temperature (MAT) & BIO1 \\
Mean Diurnal Range (MDR) & BIO2 \\
Isothermality (Iso) & BIO3 \\
Temperature Seasonality (TS) & BIO4 \\
BIO5 \\
Max Temperature of Warmest Month (Tmax) & BIO6 \\
Min Temperature of Coldest Month (Tmin) & BIO7 \\
Temperature Annual Range (ATR) & BIO8 \\
Mean Temperature of Wettest Quarter (MTWeQ) & BIO9 \\
Mean Temperature of Driest Quarter (MTDQ) & BIO10 \\
Mean Temperature of Warmest Quarter (MTWaQ) & BIO11 \\
Mean Temperature of Coldest Quarter (MTCQ) & BIO12 \\
Annual Precipitation (PA) & BIO13 \\
Precipitation of Wettest Month (PWM) & BIO14 \\
Precipitation of Driest Month (PDM) & BIO15 \\
Precipitation Seasonality (PS) & BIO16 \\
Precipitation of Wettest Quarter (PWeQ) & BIO17 \\
Precipitation of Driest Quarter (PDQ) & BIO18 \\
Precipitation of Warmest Quarter (PWaQ) & BIO19 \\
Precipitation of Coldest Quarter (PCQ) &
\end{tabular}

Table 2. WorldClim variables, abbreviations and numbers for the climate variables used in the analysis of size and MASH similarity of ant genomes.

One study of the evolution of the subfamily Myrmicinae observed that the genus as a whole could be split into at least four different lineages (Ward et al., 2015). Another, more detailed study of the genus in North America found that multiple individuals of A. rudis separated out into distinct groupings, each with other species, specifically, individuals of A. rudis from North Carolina (USA) were observed to form distinct clusters with individuals of $A$. carolinensis, A. miamiana, A. lamellidens and A. texana (DeMarco and Cognato, 2016).

\section{Biogeographic Patterns of Ant Genomes}

\begin{tabular}{|c|c|c|c|c|c|c|c|}
\hline & A. ashmeadi & A. floridana & A. fulva & A. miamiana & A. picea & A. rudis 1 & A. rudis2 \\
\hline Total Scaffold Length (Mb) & 310.33 & 382.86 & 346.13 & 342.64 & 386.04 & 395.41 & 429.70 \\
\hline Coverage $(\%)$ & 81.46 & 71.88 & 70.70 & 77.40 & 67.47 & 66.49 & 65.59 \\
\hline Scaffold N50 (bp) & 336807.00 & 439114.00 & 255328.00 & 351517.00 & 322984.00 & 300103.00 & 269776.00 \\
\hline Scaffolds & 5087.00 & 6422.00 & 7031.00 & 6920.00 & 6808.00 & 7404.00 & 7665.00 \\
\hline Max Gap (bp) & 13070.00 & 15108.00 & 12104.00 & 11453.00 & 14952.00 & 18586.00 & 24564.00 \\
\hline Captured Gaps & 26350.00 & 30858.00 & 32881.00 & 28801.00 & 36417.00 & 34062.00 & 34313.00 \\
\hline Total Gap Length (Mb) & 57.69 & 107.89 & 101.40 & 77.64 & 125.15 & 131.71 & 148.75 \\
\hline Total Contig Length $(\mathrm{Mb})$ & 252.64 & 274.96 & 244.73 & 265.00 & 260.90 & 263.70 & 280.95 \\
\hline Contig N50 (bp) & 21677.00 & 23448.00 & 15753.00 & 20738.00 & 15440.00 & 15622.00 & 18941.00 \\
\hline Contigs & 31437.00 & 37280.00 & 39912.00 & 35721.00 & 43225.00 & 41466.00 & 41978.00 \\
\hline Assembly GC (\%) & 38.27 & 38.03 & 38.39 & 38.21 & 38.32 & 38.25 & 37.88 \\
\hline Contaminants (\%) & 0.30 & 0.24 & 0.02 & 0.26 & 1.14 & 1.25 & 0.61 \\
\hline
\end{tabular}

Table 3. Sequencing statistics for the genomes of the sequenced colonies of Aphaenogaster.

After controlling for both spatial autocorrelation and potential phylogenetic patterns, we found a marginally significant, positive correlation between ant assembly size similarity and climate similarity (Mantel $\mathrm{R}=0.12, p$-value $=0.068)$. Although assembly size similarity and MASH genome similarity were not significantly correlated ( $p$-value $=0.126)$, we included MASH as a covariate in addition to geodesic 
A

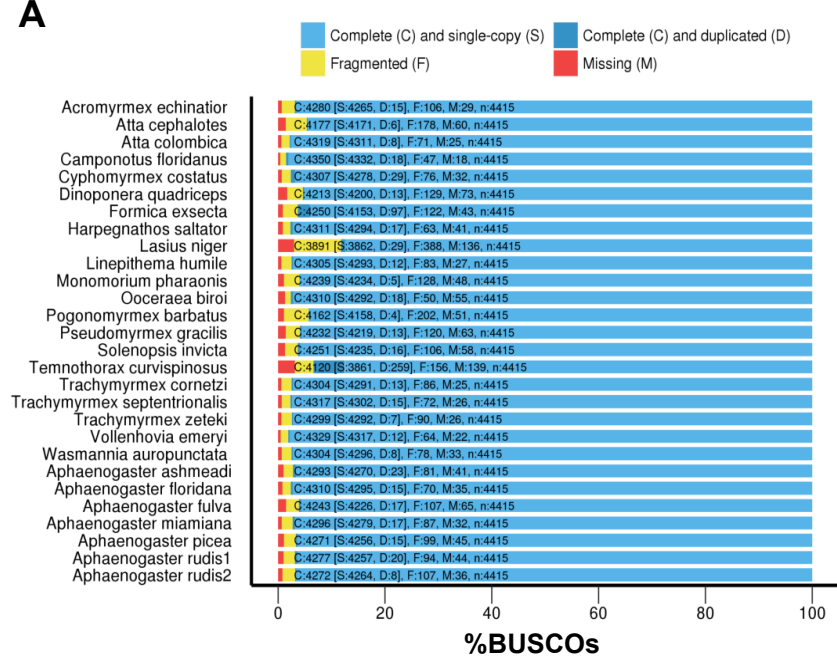

B

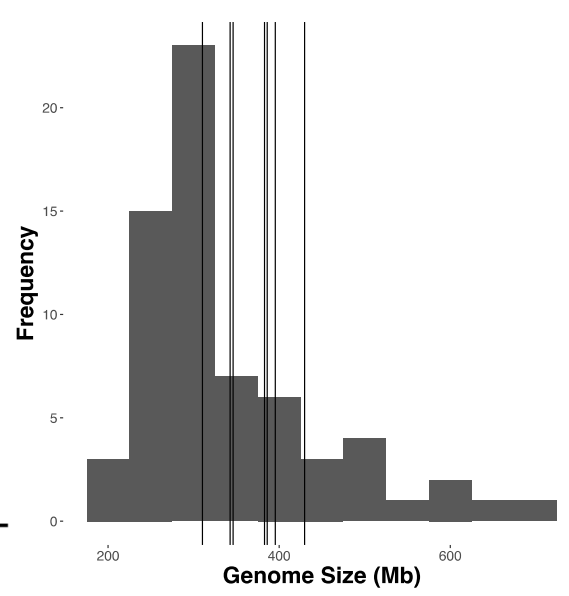

Figure 4. The Aphaenogaster genomes displayed a high degree of completeness and were within the size range of previously published ant genomes. A) Stacked bar plot of the BUSCO metrics including the number and percentage of complete Hymenoptera (ODB9) BUSCOs (C), also including both single (S) and duplicated (D) copies, as well as fragmented (F) and missing (M) out of 4415 BUSCOs for the Aphaenogaster and previously published ant genomes available from NCBI (accessed August 2018). B) Frequency distribution of previously published genome size estimates using flow cytometry from Tsutsui et al. (2008) and those available in the NCBI Genomes database. Vertical lines identify the sizes of the Aphaenogaster assemblies (see Table 3)

distance because previous research indicated that genome size is associated with phylogenetic relatedness (Alfsnes et al., 2017). We found that different spatial and climatic variables were associated with the size similarity of ant genomes. Longitude but not latitude was a significant predictor of assembly size similarity (Table 4). Temperature of the coldest (Tmin) and hottest (Tmax) month and total annual precipitation (PA), were significant predictors, but neither mean annual temperature (MAT) nor precipitation seasonality (PS) were significant predictors of assembly size similarity. Overall, Tmin and PA had the strongest relationships with assembly size similarity with both exhibiting generally negative relationships with size (Fig 6). When the newly sequenced Aphaenogaster genomes were excluded from the analysis, only annual precipitation (PA) was a significant predictor of assembly size similarity $\left(R^{2}=0.31, p\right.$-value $=$ 0.020 and see Supplementary Materials Table 2). 


\begin{tabular}{lrrrrrr}
\hline & $d f$ & $S S$ & $M S$ & Pseudo- $F$ & $R 2$ & $\mathrm{p}$-value \\
\hline Assembly Size Similarity & & & & & & \\
Lat & 1 & 2428.30 & 2428.30 & 1.70 & 0.03 & 0.2093 \\
Lon & 1 & 9528.44 & 9528.44 & 6.67 & 0.11 & 0.0165 \\
MAT & 1 & 147.67 & 147.67 & 0.10 & 0.00 & 0.7531 \\
Tmin & 1 & 18869.62 & 18869.62 & 13.22 & 0.22 & 0.0029 \\
Tmax & 1 & 8994.04 & 8994.04 & 6.30 & 0.11 & 0.0230 \\
PA & 1 & 22424.69 & 22424.69 & 15.71 & 0.26 & 0.0011 \\
PS & 1 & 1062.82 & 1062.82 & 0.74 & 0.01 & 0.4132 \\
Residuals & 15 & 21414.46 & 1427.63 & & 0.25 & \\
Total & 22 & 84870.04 & & & 1.00 & \\
\hline
\end{tabular}

Table 4. PerMANOVA pseudo-F table for the analysis of the relationship between climate variables and ant assembly size similarity. 


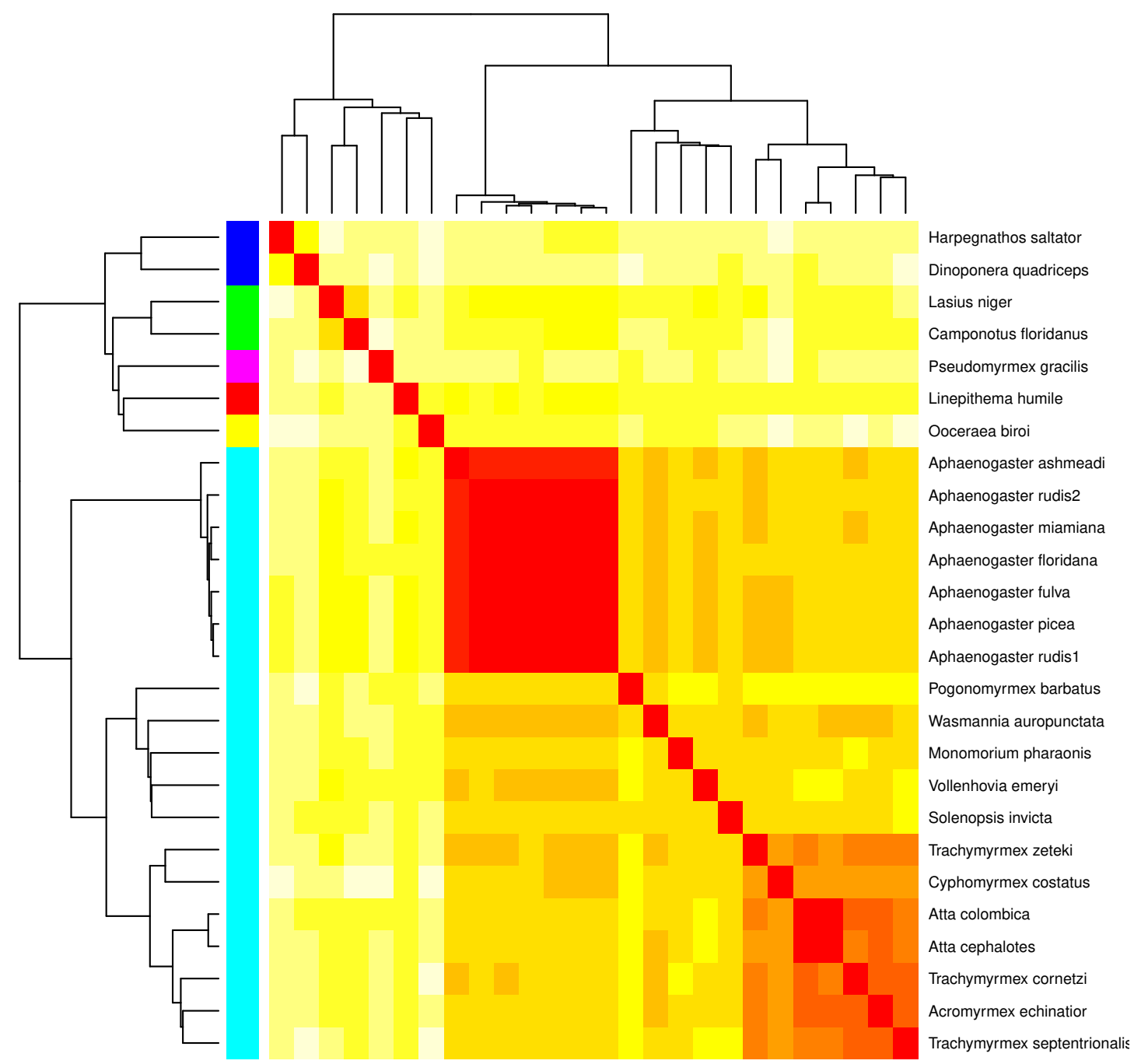

Figure 5. Heatmap of the MASH genomic distances of the Aphaenogaster species that we sampled together with other ant species in NCBIs. Heat colors shown in the central matrix range from high (white $=1$ ) through moderate (orange $=0.5)$ to low $($ red $=0$ ) genomic distance; the diagonal is entirely red because it illustrates the distance of each sequence to itself. The cladograms on the left and top show hierarchical clustering of the genomes. Colors shown to the left of the matrix indicate ant subfamilies: Ponerinae (dark blue), Formicinae (green), Pseudomyrmecinae (pink), Dolichoderinae (red), Dorylinae (yellow), Myrmicinae (light blue). 


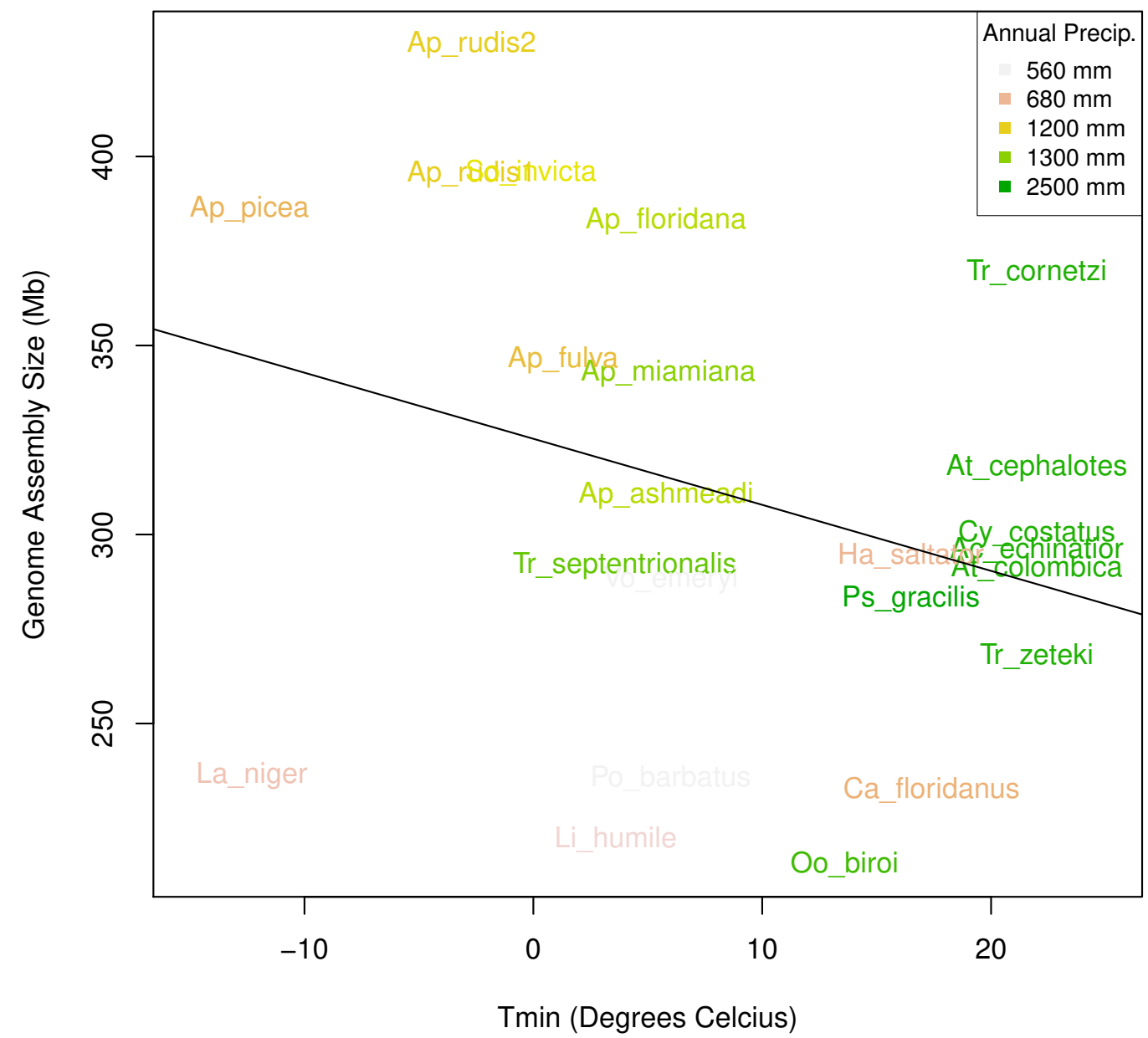

Figure 6. Bivariate plot showing the relationship between ant assembly size and minimum temperature of the coldest month (Tmin) with Annual Precipitation (PA) overlaid as colors. Ants from locations with lower minimum temperatures and annual precipitation tended to have larger genomes. 


\section{DISCUSSION}

We have produced seven draft whole-genome sequences of six species of ants in the genus Aphaenogaster. The addition of the Aphaenogaster sequences increases the breadth of global ant genomic sampling, as these are the first whole-genomes from a previously un-sequenced genus, adding to the sequences of the diverse "formicoid" clade, which contains $90 \%$ of all extant ant species (Ward, 2014). Our genomic sequences were comparable in quality to other ant and insect genomes and the patterns of genomic similarity were in line with expectations based on current ant systematics. With the addition of the new Aphaenogaster sequences, our initial biogeographic analysis revealed that ant genomes from more similar climates have more similarly sized genomes with minimum temperatures having the strongest correlation with genome size, which is consistent with the hypothesis that climate has been a force shaping ant genome size.

Although correlative, our genome analysis results are consistent with the hypothesis that ants from regions with more similar climates tend to have similar sized genomes. Previous studies have observed physiological and ecological responses of ants to climate gradients and shifting temperatures (Warren and Chick, 2013; Stanton-Geddes et al., 2016; Diamond et al., 2016; Nguyen et al., 2017; Helms Cahan et al., 2017; Diamond et al., 2017; Penick et al., 2017) that could act as agents of selection or as environmental filters. For example, Warren and Chick (2013) found that cold, but not warm, temperatures limited shifts in the distributions of $A$. picea and A. rudis. Diamond et al. (2016) reported that the rate of colonization and occupancy of nests by Aphaenogaster species in a five-year experimental warming study (Pelini et al., 2014) declined with temperature in the warm, southern study site (Duke Forest, NC, USA) but not in the cooler, northern study site (Harvard Forest, MA, USA). In addition to the direct impacts of climate, some studies support the importance for the indirect effects of climate via biotic interactions. For example, the distribution of the species Atta texana is limited by the cold-tolerance of its fungal symbiont, cultivars of the genus Attamyces (Mueller et al., 2011). The evolution of the ant-fungus relationship has led to reductions in some ant species ranges by cold temperatures.

Although we found support for increasing genome size with colder temperatures and annual precipitation, we are cautious to offer possible mechanisms for these patterns. In addition to these variables themselves being correlated, in general arthropod genome size appears to be influenced by a complex array of selection pressures. This is evidenced by the recent study by Alfsnes et al. (2017), which found that genome size patterns varied greatly among major arthropod taxa with high potential for different mechanisms affecting genome size. For example, insects displayed clear phylogenetic correlations with genome size while genome size patterns in crustaceans were nearly independent of phylogeny but strongly related to biogeographic gradients (e.g. decreasing genome size with increasing maximum observed 
latitude). In addition, Hultgren et al. (2018) found evidence for increasing genome size with latitude in crustaceans but not decapods, adding another example of the potential complexity of genome size as an adaptive trait.

There is the potential for both direct and indirect selection for increased genome size in colder conditions. Hessen et al. (2010) has proposed that there is a complex set of relationships among genome size, developmental rate, cell size and body size and that selection can act at different points in this causal network. One possible direct pathway is that increased expression of gene products that deal with cold stress could lead to larger genomes via whole genome or individual gene duplications Dufresne and Jeffery (2011). Previous work with Aphaenogaster supports this hypothesis, as Stanton-Geddes et al. (2016) found that exposure to extreme cold induced expression of genes in the cold-climate A. picea more so than in A. carolinensis (a more southern, warm climate species). An example of a possible indirect pathway is that cold could select for increased body size to deal with heat-loss in cold conditions (Brown et al., 2004), which could lead to larger genome sizes. There is evidence of cold selecting for greater body size (i.e. Bergmann's Rule) in ants (Heinze et al., 2003; Bernadou et al., 2016), and some have hypothesized that increased body size could lead indirectly to increased genome size via increased cell size (Ryan Gregory, 2005); however, the most recent, broad analysis of genome size in ants (that we are aware of) did not find support for a relationship between ant genome size and body size after controlling for phylogenetic patterns (Tsutsui et al., 2008). Therefore, assuming that our analysis adequately controlled for phylogenetics, indirect selection on genome size via body size is not a likely explanation for our observed relationship between genome size and temperature.

It is important to keep in mind that the climate related genomic patterns observed in this study should be considered an initial view of possible biogeographic patterns in ant genomes. As the addition of the these sequences had a marked impact on the statistical results of the climate analysis (see Supplementary Materials Table 2), we expect that further sequencing work will continue to enhance our understanding of the ecological genomics of ants. Also, these findings should be tested with additional sequencing efforts, as we could not control for several potentially important intercorrelated variables. Factors such as sampling bias and sequencing methodology (e.g. 454 versus Illumina) also varied among sequencing efforts, which could have contributed to some of the observed correlations with climate. We did not attempt to control for these factors statistically due to the limitations of the current ant genome sample size. Future work should methodologically and/or statistically control for such sources of variation in ant genomes as more sequences become available to elucidate clearer patterns and resolve underlying ecological and evolutionary mechanisms. 


\section{CONCLUSION}

Although we have increased the total number of sequenced ant genomes by over $30 \%$, the total number of ant sequences analyzed here is still a relatively small sample $(n=26)$ of the estimated $>16,000$ ant species and subspecies (www.antweb.org, accessed 20 Aug 2018). Efforts such as The Global Ant Genomics Alliance (GAGA)(Boomsma et al., 2017), which aims to greatly increase the number of ant species sequenced from across the world, will provide additional resources for ecological genomics studies. Further work investigating the variation in genomic content and mapping of target coding regions from previous physiological (Nguyen et al., 2017), biochemical (Helms Cahan et al., 2017), and transcriptomic (Stanton-Geddes et al., 2016) studies of Aphaenogaster and other ant species will inform predictions of how these species, and the ecosystems that they inhabit, may respond to ongoing climatic change. For instance, determining the genomic factors underlying the temperature response of ant assemblages to climatic gradients (Warren and Chick, 2013; Diamond et al., 2016, 2017) could provide useful insights into the response of these important organisms to non-analog ecosystem states and idiosyncratic community responses (Bewick et al., 2014). In addition, as species distribution models have been significantly improved by the inclusion of genetic information (Ikeda et al., 2016), an ecological genetics approach that couples ant genomic and ecologically relevant data will provide a useful window into the response of many terrestrial ecosystems to a changing climate.

\section{ACKNOWLEDGMENTS}

Thank you to the genome sequencing team at the Broad Institute (particularly, James Bochicchio, Sarah Young, Terrance Shay and Caroline Cusick) and to Manisha Patel at Harvard Forest's Torrey Lab for assistance in obtaining and properly storing ant colonies. 


\section{REFERENCES}

Agosti, D., Majer, J. D., Alonso, L. E., and Schultz, T. R. (2000). Standard methods for measuring and monitoring biodiversity, volume 233. Smithsonian Institution Press.

Alfsnes, K., Leinaas, H. P., and Hessen, D. O. (2017). Genome size in arthropods; different roles of phylogeny, habitat and life history in insects and crustaceans. Ecol. Evol., 7(15):5939-5947.

Anderson, M. J. (2001). A new method for non-parametric multivariate analysis of variance. Austral Ecol., 26(1):32-46.

Bernadou, A., Römermann, C., Gratiashvili, N., and Heinze, J. (2016). Body size but not colony size increases with altitude in the holarctic ant, Leptothorax acervorum. Ecol. Entomol., 41(6):733-736.

Bewick, S., Stuble, K. L., Lessard, J.-P., Dunn, R. R., Adler, F. R., and Sanders, N. J. (2014). Predicting future coexistence in a North American ant community. Ecol. Evol., 4(10):1804-1819.

Bolton, B. (2006). Bolton's catalogue of ants of the world, 1758-2005. Harvard University Press.

Boomsma, J. J., Brady, S. G., Dunn, R. R., Gadau, J., Heinze, J., Keller, L., Moreau, C. S., Sanders, N. J., Schrader, L., Schultz, T. R., Sundström, L., Ward, P. S., Wcislo, W. T., and Zhang, G. (2017). The Global Ant Genomics Alliance (GAGA). Myrmecological News, 25:61-66.

Brown, J. H., Gillooly, J. F., Allen, A. P., Savage, V. M., and West, G. B. (2004). Toward a metabolic theory of ecology. Ecology.

Brown, P. T. and Caldeira, K. (2017). Greater future global warming inferred from Earth's recent energy budget. Nature, 552(7683):45-50.

Burrows, M. T., Schoeman, D. S., Richardson, A. J., Molinos, J. G., Hoffmann, A., Buckley, L. B., Moore, P. J., Brown, C. J., Bruno, J. F., Duarte, C. M., Halpern, B. S., Hoegh-Guldberg, O., Kappel, C. V., Kiessling, W., O'Connor, M. I., Pandolfi, J. M., Parmesan, C., Sydeman, W. J., Ferrier, S., Williams, K. J., and Poloczanska, E. S. (2014). Geographical limits to species-range shifts are suggested by climate velocity. Nature, 507(7493):492-495.

Cook, R. D. and Weisberg, S. (1982). Residuals and influence in regression. Chapman and Hall.

Del Toro, I., Ribbons, R. R., and Pelini, S. L. (2012). The little things that run the world revisited: A review of ant-mediated ecosystem services and disservices (Hymenoptera: Formicidae). Myrmecological News, 17:133-146.

DeMarco, B. B. and Cognato, A. I. (2016). A multiple-gene phylogeny reveals polyphyly among eastern North American Aphaenogaster species (Hymenoptera: Formicidae). Zool. Scr., 45(5):512-520.

Des Roches, S., Post, D. M., Turley, N. E., Bailey, J. K., Hendry, A. P., Kinnison, M. T., Schweitzer, J. A., and Palkovacs, E. P. (2017). The ecological importance of intraspecific variation. Nat. Ecol. Evol.

Diamond, S. E., Chick, L., Penick, C. A., Nichols, L. M., Cahan, S. H., Dunn, R. R., Ellison, A. M., 
Sanders, N. J., and Gotelli, N. J. (2017). Heat tolerance predicts the importance of species interaction effects as the climate changes. Integr. Comp. Biol., 57(1):112-120.

Diamond, S. E. and Chick, L. D. (2018). Thermal specialist ant species have restricted, equatorial geographic ranges: Implications for climate change vulnerability and risk of extinction. Ecography (Cop.).

Diamond, S. E., Nichols, L. M., Pelini, S. L., Penick, C. A., Barber, G. W., Cahan, S. H., Dunn, R. R., Ellison, A. M., Sanders, N. J., and Gotelli, N. J. (2016). Climatic warming destabilizes forest ant communities. Sci. Adv., 2(10):e1600842-e1600842.

Diamond, S. E., Sorger, D. M., Hulcr, J., Pelini, S. L., Toro, I. D., Hirsch, C., Oberg, E., and Dunn, R. R. (2012). Who likes it hot? A global analysis of the climatic, ecological, and evolutionary determinants of warming tolerance in ants. Glob. Chang. Biol., 18(2):448-456.

Dufresne, F. and Jeffery, N. (2011). A guided tour of large genome size in animals: what we know and where we are heading. Chromosom. Res., 19(7):925-938.

Ellison, A. M. (2012). A field guide to the ants of New England. Yale University Press.

Fick, S. E. and Hijmans, R. J. (2017). WorldClim 2: new 1-km spatial resolution climate surfaces for global land areas. Int. J. Climatol., 37(12):4302-4315.

Gnerre, S., Maccallum, I., Przybylski, D., Ribeiro, F. J., Burton, J. N., Walker, B. J., Sharpe, T., Hall, G., Shea, T. P., Sykes, S., Berlin, A. M., Aird, D., Costello, M., Daza, R., Williams, L., Nicol, R., Gnirke, A., Nusbaum, C., Lander, E. S., and Jaffe, D. B. (2011). High-quality draft assemblies of mammalian genomes from massively parallel sequence data. Proc. Natl. Acad. Sci. U. S. A., 108(4):1513-8.

Goslee, S. C. and Urban, D. L. (2007). The ecodist Package for Dissimilarity-based Analysis of Ecological Data. J. Stat. Softw., 22(7):1-19.

Hare, E. E. and Johnston, J. S. (2011). Genome Size Determination Using Flow Cytometry of Propidium Iodide-Stained Nuclei. Mol. Methods Evol. Genet., 772(5):3-12.

Heinze, J., Foitzik, S., Fischer, B., Wanke, T., and Kipyatkov, V. E. (2003). The significance of latitudinal variation in body size in a holarctic ant, Leptothorax acervorum. Ecography (Cop.)., 26(3):349-355.

Helms Cahan, S., Nguyen, A. D., Stanton-Geddes, J., Penick, C. A., Hernáiz-Hernández, Y., DeMarco, B. B., and Gotelli, N. J. (2017). Modulation of the heat shock response is associated with acclimation to novel temperatures but not adaptation to climatic variation in the ants Aphaenogaster picea and A. rudis. Comp. Biochem. Physiol. Part A Mol. Integr. Physiol., 204:113-120.

Hessen, D. O., Jeyasingh, P. D., Neiman, M., and Weider, L. J. (2010). Genome streamlining and the elemental costs of growth. Trends Ecol. Evol., 25:75-80.

Hultgren, K. M., Jeffery, N. W., Moran, A., and Gregory, T. R. (2018). Latitudinal variation in genome 
size in crustaceans. Biol. J. Linn. Soc., 123(2):348-359.

Ikeda, D. H., Max, T. L., Allan, G. J., Lau, M. K., Shuster, S. M., and Whitham, T. G. (2016). Genetically informed ecological niche models improve climate change predictions. Glob. Chang. Biol., 23(1):164176.

Kaspari, M., Clay, N. A., Lucas, J. A., Revzen, S., Kay, A. D., and Yanoviak, S. P. (2015). Thermal adaptation and phosphorus shape thermal performance in an assemblage of rainforest ants. Ecology, 97(4):15-1225.1.

Libbrecht, R., Oxley, P. R., Kronauer, D. J. C., and Keller, L. (2013). Ant genomics sheds light on the molecular regulation of social organization. Genome Biol., 14(7):212.

Moreau, C. S. (2006). Phylogeny of the Ants: Diversification in the Age of Angiosperms. Eur. J. Biochem. Eur. J. Biochem. J. Steroid Biochem. Mol. Cell Nat. Sci. N. Gompel, B. Prud'hom. Nat. J. Piatigorsky, Ann. N.Y. Acad. Sci. Sci., 101(281):1249-481.

Mousseau, T. A. (1997). Ectotherms Follow the Converse to Bergmann's Rule. Evolution (N. Y)., 51(2):630.

Mueller, U. G., Mikheyev, A. S., Hong, E., Sen, R., Warren, D. L., Solomon, S. E., Ishak, H. D., Cooper, M., Miller, J. L., Shaffer, K. A., and Juenger, T. E. (2011). Evolution of cold-tolerant fungal symbionts permits winter fungiculture by leafcutter ants at the northern frontier of a tropical ant-fungus symbiosis. Proc. Natl. Acad. Sci., 108(10):4053-4056.

Neafsey, D. E., Lawniczak, M. K. N., Park, D. J., Redmond, S. N., Coulibaly, M. B., Traoré, S. F., Sagnon, N., Costantini, C., Johnson, C., Wiegand, R. C., Collins, F. H., Lander, E. S., Wirth, D. F., Kafatos, F. C., Besansky, N. J., Christophides, G. K., and Muskavitch, M. A. T. (2010). SNP genotyping defines complex gene-flow boundaries among African malaria vector mosquitoes. Science, 330(6003):514-517.

Nguyen, A. D., DeNovellis, K., Resendez, S., Pustilnik, J. D., Gotelli, N. J., Parker, J. D., and Cahan, S. H. (2017). Effects of desiccation and starvation on thermal tolerance and the heat-shock response in forest ants. J. Comp. Physiol. B, 187(8):1107-1116.

Nygaard, S. and Wurm, Y. (2015). Ant genomics (Hymenoptera: Formicidae): Challenges to overcome and opportunities to seize. Myrmecological News, 21:59-72.

Oksanen, J., Blanchet, F., Kindt, R., Legendre, P., and O’Hara, R. (2016). Vegan: community ecology package.

Ondov, B. D., Treangen, T. J., Melsted, P., Mallonee, A. B., Bergman, N. H., Koren, S., and Phillippy, A. M. (2016). Mash: fast genome and metagenome distance estimation using MinHash. Genome Biol., 17(1):132.

Parmesan, C. (2006). Ecological and Evolutionary Responses to Recent Climate Change. Annu. Rev. 
Ecol. Evol. Syst., 37(1):637-669.

Pelini, S. L., Diamond, S. E., Nichols, L. M., Stuble, K. L., Ellison, A. M., Sanders, N. J., Dunn, R. R., and Gotelli, N. J. (2014). Geographic differences in effects of experimental warming on ant species diversity and community composition. Ecosphere, 5(10):art125.

Penick, C. A., Diamond, S. E., Sanders, N. J., and Dunn, R. R. (2017). Beyond thermal limits: comprehensive metrics of performance identify key axes of thermal adaptation in ants. Funct. Ecol., 31(5):1091-1100.

Petrov, D. A. (2001). Evolution of genome size: new approaches to an old problem. Trends Genet., 17(1):23-28.

R Core Team (2017). R Core Team (2017). R: A language and environment for statistical computing. $R$ Found. Stat. Comput. Vienna, Austria.

Rowntree, J. K., Shuker, D. M., and Preziosi, R. F. (2011). Forward from the crossroads of ecology and evolution. Philos. Trans. R. Soc. Lond. B. Biol. Sci., 366(1569):1322-8.

Ryan Gregory, T. (2005). Genome Size Evolution in Animals. Evol. Genome.

Siddig, A. A., Ellison, A. M., Ochs, A., Villar-Leeman, C., and Lau, M. K. (2016). How do ecologists select and use indicator species to monitor ecological change? Insights from 14 years of publication in Ecological Indicators. Ecol. Indic., 60:223-230.

Spicer, M. E., Stark, A. Y., Adams, B. J., Kneale, R., Kaspari, M., and Yanoviak, S. P. (2017). Thermal constraints on foraging of tropical canopy ants. Oecologia, 183(4):1007-1017.

Stanton-Geddes, J., Nguyen, A., Chick, L., Vincent, J., Vangala, M., Dunn, R. R., Ellison, A. M., Sanders, N. J., Gotelli, N. J., and Helms Cahan, S. (2016). Thermal reactionomes reveal divergent responses to thermal extremes in warm and cool-climate ant species. BMC Genomics, 17(1):171-186.

Tsutsui, N. D., Suarez, A. V., Spagna, J. C., Johnston, J. S., Gregory, T., Evans, J., Gundersen-Rindal, D., Gardner, T., Gregory, T., Wilson, E., Hölldobler, B., Wilson, E., Li, J., Heinz, K., Johnston, J., Ross, L., Beani, L., Hughes, D., Kathirithamby, J., Geraci, N., Johnston, J., Robinson, J., Wikel, S., Hill, C., Gregory, T., Bennett, M., Leitch, I., SanMiguel, P., Gaut, B., Tikhonov, A., Nakajima, Y., Bennetzen, J., Kazazian, H., Kidwell, M., Comeron, J., Ustinova, J., Achmann, R., Cremer, S., Mayer, F., Hancock, J., Hancock, J., Toth, G., Gaspari, Z., Jurka, J., Redon, R., Ishikawa, S., Fitch, K., Feuk, L., Perry, G., Andrews, T., Fiegler, H., Shapero, M., Carson, A., Chen, W., Cho, E., Dallaire, S., Freeman, J., Gonzalez, J., Gratacos, M., Huang, J., Kalaitzopoulos, D., Komura, D., MacDonald, J., Marshall, C., Mei, R., Montgomery, L., Nishimura, K., Okamura, K., Shen, F., Somerville, M., Tchinda, J., Valsesia, A., Woodwark, C., Yang, F., Zhang, J., Zerjal, T., Zhang, J., Armengol, L., Conrad, D., Estivill, X., Tyler-Smith, C., Carter, N., Aburatani, H., Lee, C., Jones, K., Scherer, S., Hurles, M., Gregory, T., 
Gregory, T., Petrov, D., Lozovskaya, E., Hartl, D., Devos, K., Brown, J., Bennetzen, J., Bennetzen, J., Ma, J., Devos, K., Ma, J., Bennetzen, J., Oliver, M., Petrov, D., Ackerly, D., Falkowski, P., Schofield, O., Gregory, T., Hebert, P., Kolasa, J., Finston, T., Hebert, P., Foottit, R., Ferrari, J., Rai, K., Ellegren, H., Vandenbussche, R., Longmire, J., Baker, R., Organ, C., Shedlock, A., Meade, A., Pagel, M., Edwards, S., Hughes, A., Hughes, M., Reinhold, K., Gregory, T., Pittendrigh, B., Clark, J., Johnston, J., Lee, S., Romero-Severson, J., Dasch, G., Gregory, T., Weinstock, G., Robinson, G., Gibbs, R., Worley, K., Evans, J., Maleszka, R., Robertson, H., Weaver, D., Beye, M., Bork, P., Elsik, C., Hartfelder, K., Hunt, G., Zdobnov, E., Amdam, G., Bitondi, M., Collins, A., Cristino, A., Lattorff, H., Lobo, C., Moritz, R., Nunes, F., Page, R., Simoes, Z., Wheeler, D., Carninci, P., Fukuda, S., Hayashizaki, Y., Kai, C., Kawai, J., Sakazume, N., Sasaki, D., Tagami, M., Albert, S., Baggerman, G., Beggs, K., Bloch, G., Cazzamali, G., Cohen, M., Drapeau, M., Eisenhardt, D., Emore, C., Ewing, M., Fahrbach, S., Foret, S., Grimmelikhuijzen, C., Hauser, F., Hummon, A., Huybrechts, J., Jones, A., Kadowaki, T., Kaplan, N., Kucharski, R., Leboulle, G., Linial, M., Littleton, J., Mercer, A., Richmond, T., Rodriguez-Zas, S., Rubin, E., Sattelle, D., Schlipalius, D., Schoofs, L., Shemesh, Y., Sweedler, J., Velarde, R., Verleyen, P., Vierstraete, E., Williamson, M., Ament, S., Brown, S., Corona, M., Dearden, P., Dunn, W., Elekonich, M., Fujiyuki, T., Gattermeier, I., Gempe, T., Hasselmann, M., Kadowaki, T., Kage, E., Kamikouchi, A., Kubo, T., Kucharski, R., Kunieda, T., Lorenzen, M., Milshina, N., Morioka, M., Ohashi, K., Overbeek, R., Ross, C., Schioett, M., Shippy, T., Takeuchi, H., Toth, A., Willis, J., Wilson, M., Gordon, K., Letunic, I., Hackett, K., Peterson, J., Felsenfeld, A., Guyer, M., Solignac, M., Agarwala, R., Cornuet, J., Monnerot, M., Mougel, F., Reese, J., Vautrin, D., Gillespie, J., Cannone, J., Gutell, R., Johnston, J., Eisen, M., Iyer, V., Iyer, V., Kosarev, P., Mackey, A., Solovyev, V., Souvorov, A., Aronstein, K., Bilikova, K., Chen, Y., Clark, A., Decanini, L., Gelbart, W., Hetru, C., Hultmark, D., Imler, J., Jiang, H., Kanost, M., Kimura, K., Lazzaro, B., Lopez, D., Simuth, J., Thompson, G., Zou, Z., Jong, P. D., Sodergren, E., Csuros, M., Milosavljevic, A., Osoegawa, K., Richards, S., Shu, C., Duret, L., Elhaik, E., Graur, D., Anzola, J., Campbell, K., Childs, K., Collinge, D., Crosby, M., Dickens, C., Grametes, L., Grozinger, C., Jones, P., Jorda, M., Ling, X., Matthews, B., Miller, J., Mizzen, C., Peinado, M., Reid, J., Russo, S., Schroeder, A., Pierre, S. S., Wang, Y., Zhou, P., Jiang, H., Kitts, P., Ruef, B., Venkatraman, A., Zhang, L., Aquino-Perez, G., Whitfield, C., Behura, S., Berlocher, S., Sheppard, W., Smith, D., Suarez, A., Tsutsui, N., Wei, X., Wheeler, D., Havlak, P., Li, B., Liu, Y., Sodergren, E., Jolivet, A., Lee, S., Nazareth, L., Pu, L., Thorn, R., Stolc, V., Newman, T., Samanta, M., Tongprasit, W., Claudianos, C., Berenbaum, M., Biswas, S., de Graaf, D., Feyereisen, R., Johnson, R., Oakeshott, J., Ranson, H., Schuler, M., Muzny, D., Chacko, J., Davis, C., Dinh, H., Gill, R., Hernandez, J., Hines, S., Hume, J., Jackson, L., Kovar, C., Lewis, L., Miner, G., Morgan, M., Nguyen, N., Okwuonu, G., Paul, H., 
Santibanez, J., Savery, G., Svatek, A., Villasana, D., Wright, R., Consort, H., Moreau, C., Bell, C., Vila, R., Archibald, S., Pierce, N., Brady, S., Schultz, T., Fisher, B., Ward, P., Mueller, U., Gerardo, N., Aanen, D., Six, D., Schultz, T., Chapela, I., Rehner, S., Schultz, T., Mueller, U., Wetterer, J., Schultz, T., Meier, R., Gregory, T., Hebert, P., Gregory, T., Shorthouse, D., Wang, J., Jemielity, S., Uva, P., Wurm, Y., Graff, J., Keller, L., Bennett, M., Leitch, I., Price, H., Johnston, J., Abouheif, E., Reeve, J., Abouheif, E., Felsenstein, J., Purvis, A., and Rambaut, A. (2008). The evolution of genome size in ants. BMC Evol. Biol., 8(1):64.

Walker, B. J., Abeel, T., Shea, T., Priest, M., Abouelliel, A., Sakthikumar, S., Cuomo, C. A., Zeng, Q., Wortman, J., Young, S. K., and Earl, A. M. (2014). Pilon: An Integrated Tool for Comprehensive Microbial Variant Detection and Genome Assembly Improvement. PLoS One, 9(11):e112963.

Ward, P. S. (2014). The Phylogeny and Evolution of Ants. Annu. Rev. Ecol. Evol. Syst., 45(1):23-43.

Ward, P. S., Brady, S. G., Fisher, B. L., and Schultz, T. R. (2015). The evolution of myrmicine ants: phylogeny and biogeography of a hyperdiverse ant clade (Hymenoptera: Formicidae). Syst. Entomol., 40(1):61-81.

Warren, R. J. and Chick, L. (2013). Upward ant distribution shift corresponds with minimum, not maximum, temperature tolerance. Glob. Chang. Biol., 19(7):2082-2088.

Waterhouse, R. M., Seppey, M., Simão, F. A., Manni, M., Ioannidis, P., Klioutchnikov, G., Kriventseva, E. V., and Zdobnov, E. M. (2018). BUSCO Applications from Quality Assessments to Gene Prediction and Phylogenomics. Mol. Biol. Evol., 35(3):543-548. 
Figure 1 (on next page)

Frequency distribution of currently sequenced ant genomes by geographic location.

Number of ant (Formicidae) whole-genome sequences available in NCBI by country (accessed August 2018). 


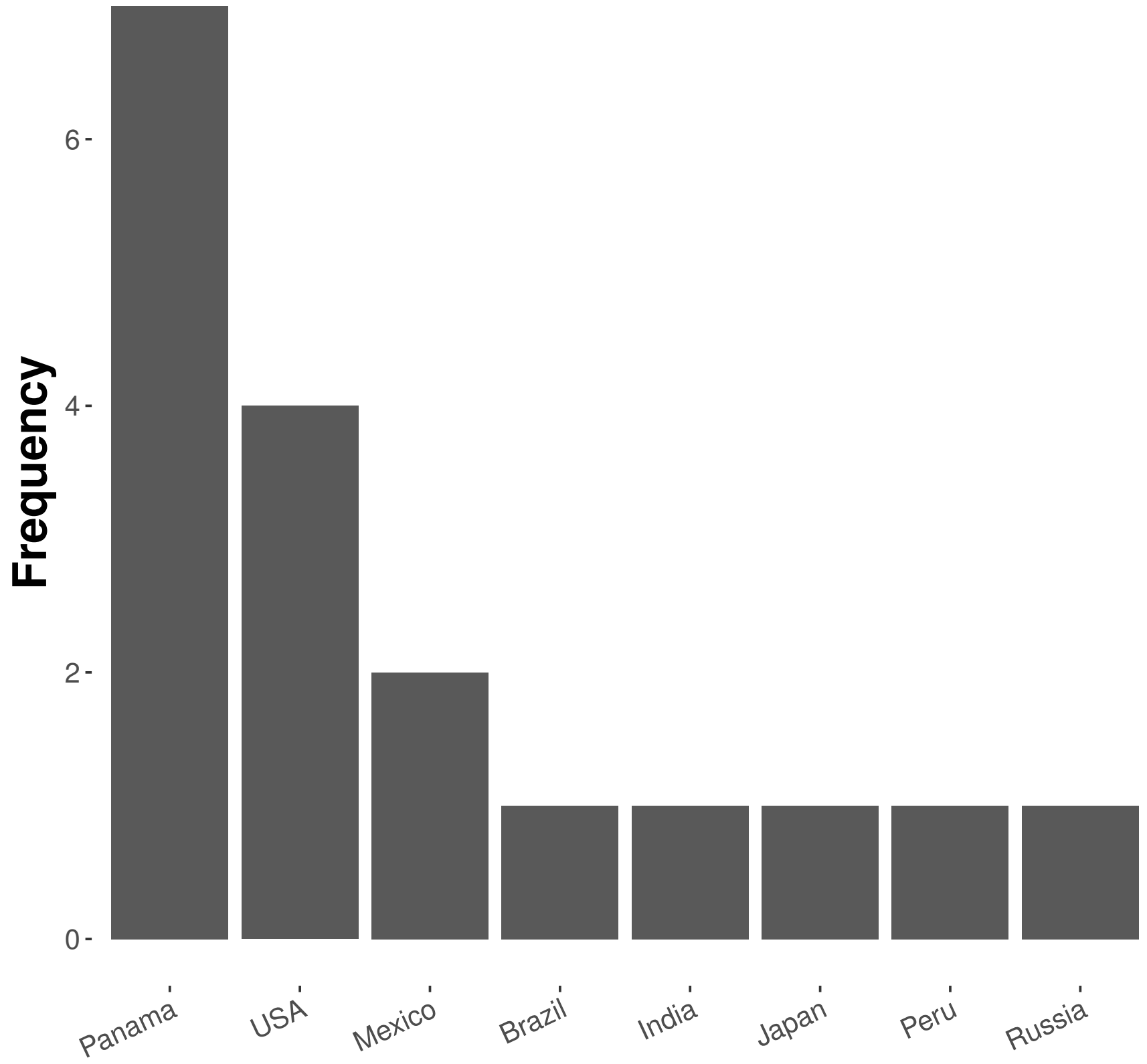




\section{Figure 2 (on next page)}

Sample location map with overlaid photos of sequenced Aphaenogaster species.

We sampled seven colonies representing six species of Aphaenogaster, including A) A. rudis, B) A. picea, C) A. floridana, D) A. fulva, E) A. miamiana and F) A. ashmeadi from G) sampling locations across eastern North America (see Table 1). All photos by April Noble (available from http://www.antweb.org). 


\section{Figure 3 (on next page)}

Heatmap of climate variable intercorrelations.

Heatmap of Pearson correlations among climate variables. Cells in the heatmap are colored by the correlation between the two variables that intersect at that location ranging from blue $=-1$ to white $=0$ to pink $=1$. The variables are arrayed by hierarchical clustering of the correlations, as shown by the dendrograms on the top and left side. For variable descriptions see Table 3. 


\section{PeerJ}

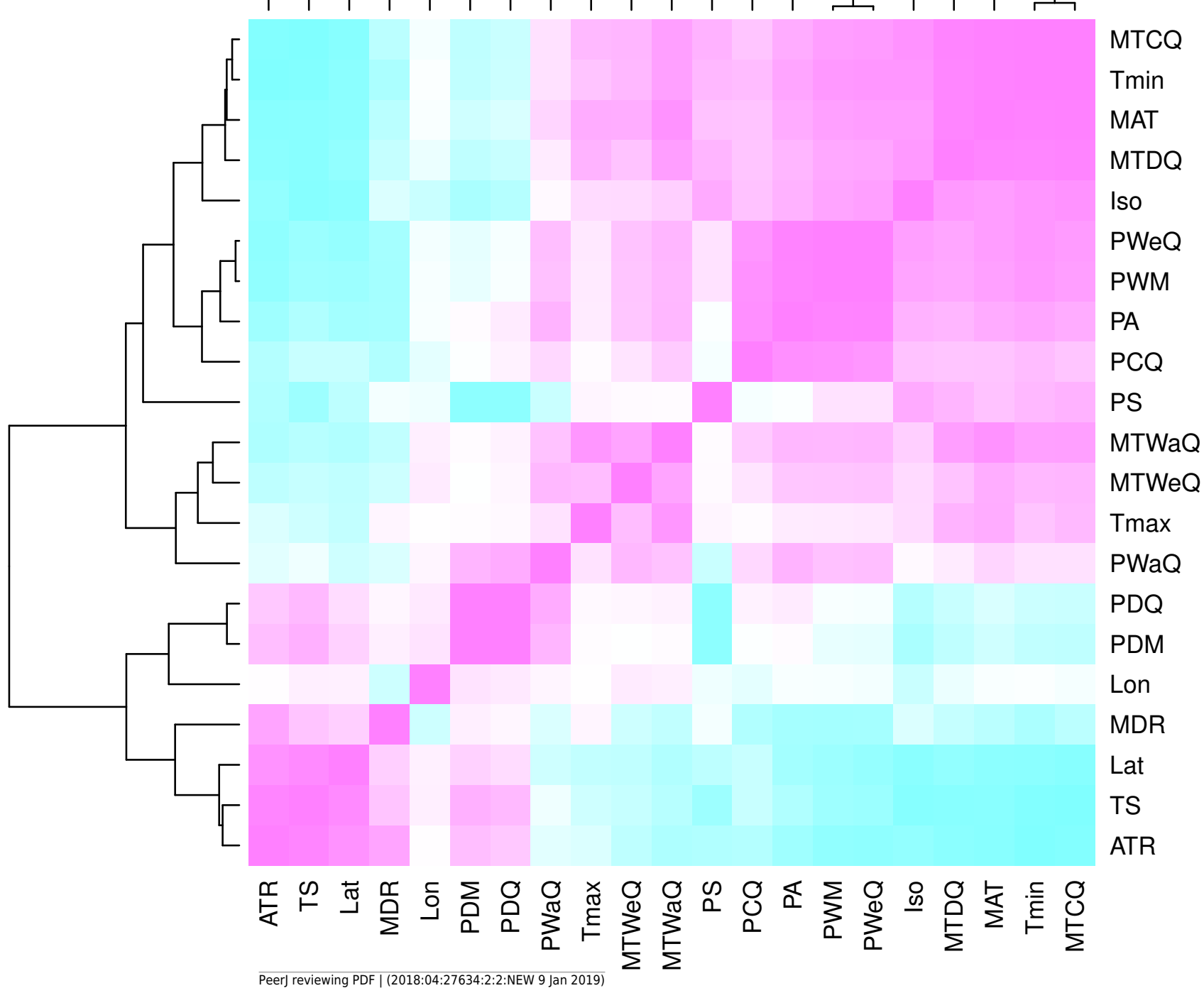




\section{Figure 4 (on next page)}

Frequency distribution of sequenced assembly and flow cytometry estimated genome sizes with overlaid Aphaenogaster genome sizes.

The Aphaenogaster genomes displayed a high degree of completeness and were within the size range of previously published ant genomes. A) Stacked bar plot of the BUSCO metrics including the number and percentage of complete Hymenoptera (ODB9) BUSCOs (C), also including both single (S) and duplicated (D) copies, as well as fragmented (F) and missing (M) out of 4415 BUSCOs for the Aphaenogaster and previously published ant genomes available from NCBI (accessed August 2018). B) Frequency distribution of previously published genome size estimates using flow cytometry from Icite \{Tsutsui2008a\} and those available in the NCBI Genomes database. Vertical lines identify the sizes of the Aphaenogaster assemblies (see Table 2). 
A

Acromyrmex echinatior Atta cephalotes Atta colombica Camponotus floridanus Cyphomyrmex costatus Dinoponera quadriceps Formica exsecta Harpegnathos saltator Lasius niger Linepithema humile Monomorium pharaonis Ooceraea birol

Pogonomyrmex barbatus Pseudomyrmex gracilis Solenopsis invicta Temnothorax curvispinosus Trachymyrmex cornetz Trachymyrmex septentrionalis

Trachymyrmex zeteki Vollenhovia emeryi

Wasmannia auropunctata Aphaenogaster ashmead Aphaenogaster floridana Aphaenogaster fulva

Aphaenogaster miamiana

Aphaenogaster picea Aphaenogaster rudis 1 Aphaenogaster rudis2
Complete (C) and single-copy (S) Fragmented (F) S) Complete (C) and duplicated (D) Missing (M)

B

| C:4280 [S:4265, D:15], F:106, M:29, n:4415

C:4177 [S:4171, D:6], F:178, M:60, n:4415

I C:4319 [S:4311, D:8], F:71, M:25, n:4415

| C:4350 [S:4332, D:18], F:47, M:18, n:4415

I C: $: 407$ [S:4278, D:29], F:76, M:32, n:4415

C:4213 [S:4200, D:13], F:129, M:73, n:4415

C:4250 [S:4153, D:97], F:122, M:43, n:4415

| C:4311 [S:4294, D:17], F:63, M:41, n:4415

C:3891 [S:3862, D:29], F:388, M:136, n:4415

II C:4305 [S:4293, D:12], F:83, M:27, n:4415

C:4239 [S:4234, D:5], F:128, M:48, n:4415

IC:4310 [S:4292, D:18], F:50, M:55, n:4415

C:4162 [S:4158, D:4], F:202, M:51, n:4415

d:4232 [S:4219, D:13], F:120, M:63, n:4415

C:4251 [S:4235, D:16], F:106, M:58, n:4415

C:4120 [S:3861, D:259], F:156, M:139, n:4415

I C:4304 [S:4291, D:13], F:86, M:25, n:4415

I C:4317 [S:4302, D:15], F:72, M:26, n:4415

| C:4299 [S:4292, D:7], F:90, M:26, n:4415

| C:4329 [S:4317, D:12], F:64, M:22, n:4415

I C:4304 [S:4296, D:8], F:78, M:33, n:4415

C:4293 [S:4270, D:23], F:81, M:41, n:4415

I C:4310 [S:4295, D:15], F:70, M:35, n:4415

C:4243 [S:4226, D:17], F:107, M:65, n:4415

C:4296 [S:4279, D:17], F:87, M:32, n:4415

C:4271 [S:4256, D:15], F:99, M:45, n:4415

C:4277 [S:4257, D:20], F:94, M:44, n:4415

C:4272 [S:4264, D:8], F:107, M:36, n:4415

40

$\%$ BUSCOs

60
20

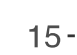

중

$0-$ 100

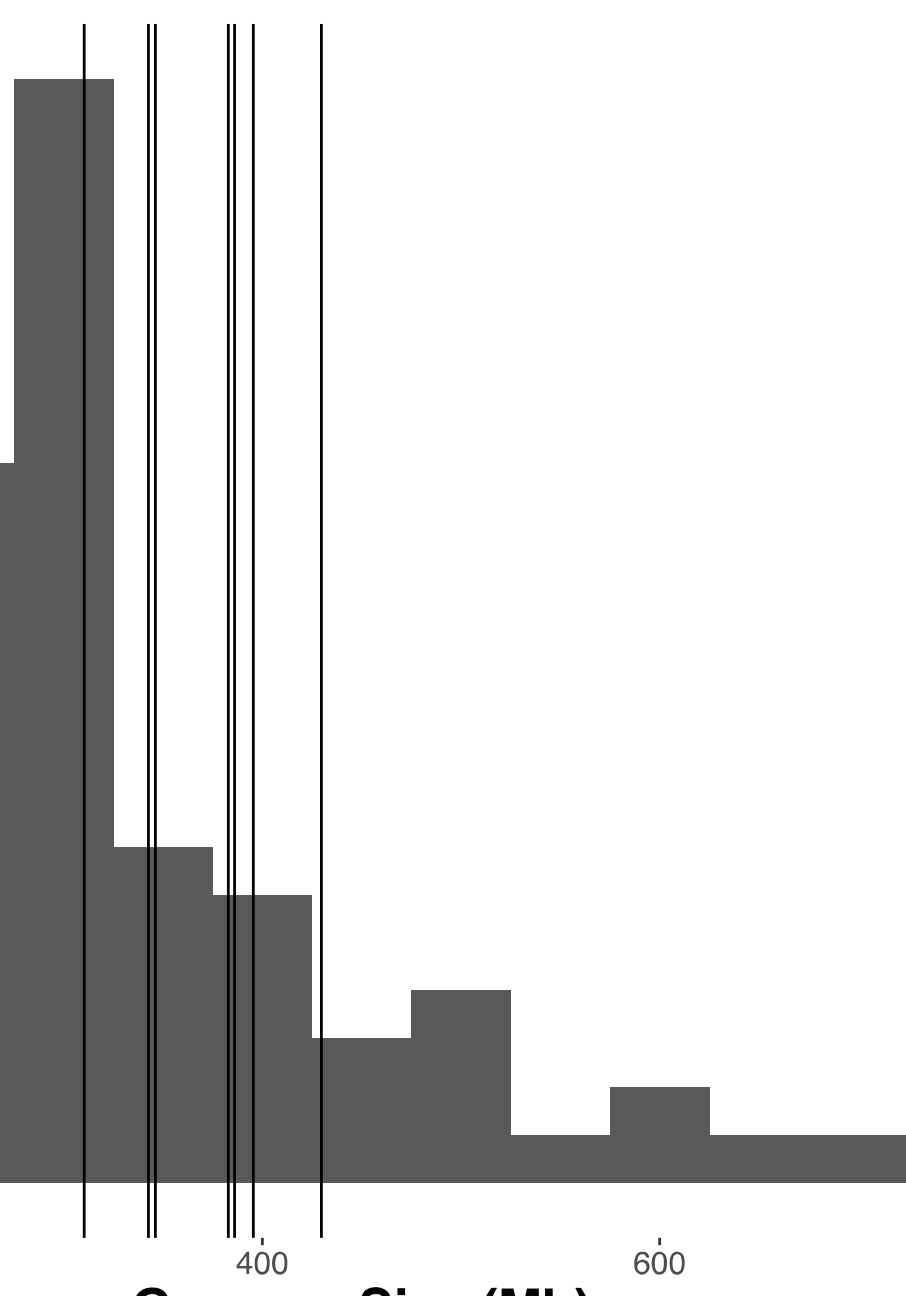

Genome Size (Mb) 


\section{Figure $\mathbf{5}$ (on next page)}

Heatmap of MASH genomic distances for all sequenced ant genomes.

Heatmap of the MASH genomic distances of the Aphaenogaster species that we sampled together with other ant species in NCBIs. Heat colors shown in the central matrix range from high (white $=1$ ) through moderate (orange $=0.5$ ) to low (red $=0$ ) genomic distance; the diagonal is entirely red because it illustrates the distance of each sequence to itself. The cladograms on the left and top show hierarchical clustering of the genomes. Colors shown to the left of the matrix indicate ant subfamilies: Ponerinae (dark blue), Formicinae (green), Pseudomyrmecinae (pink), Dolichoderinae (red), Dorylinae (yellow), Myrmicinae (light blue). 


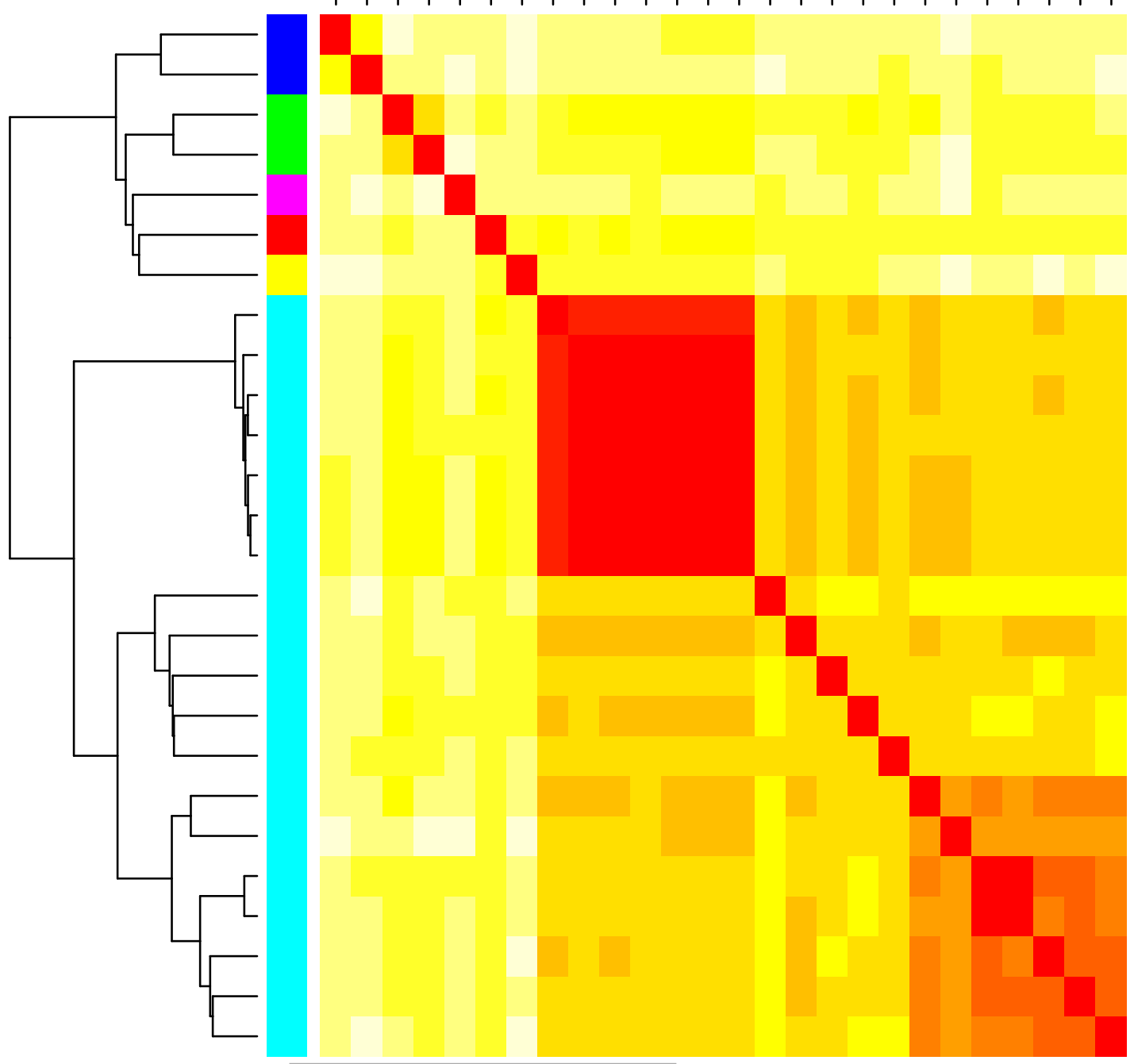

Harpegnathos saltator Dinoponera quadriceps Lasius niger

Camponotus floridanus Pseudomyrmex gracilis Linepithema humile Ooceraea biroi Aphaenogaster ashmeadi Aphaenogaster rudis2 Aphaenogaster miamiana Aphaenogaster floridana Aphaenogaster fulva Aphaenogaster picea Aphaenogaster rudis1 Pogonomyrmex barbatus Wasmannia auropunctata Monomorium pharaonis Vollenhovia emeryi Solenopsis invicta Trachymyrmex zeteki Cyphomyrmex costatus Atta colombica Atta cephalotes Trachymyrmex cornetzi Acromyrmex echinatior Trachymyrmex septentrionalis 
Figure $\mathbf{6}$ (on next page)

Bivariate plot of the correlation between sampling location minimum temperature of the coldest month (Tmin), annual precipitation (PA) and genome size.

Bivariate plot showing the relationship between ant assembly size and minimum temperature of the coldest month (Tmin) with Annual Precipitation (PA) overlaid as colors. Ants from locations with lower minimum temperatures and annual precipitation tended to have larger genomes. 


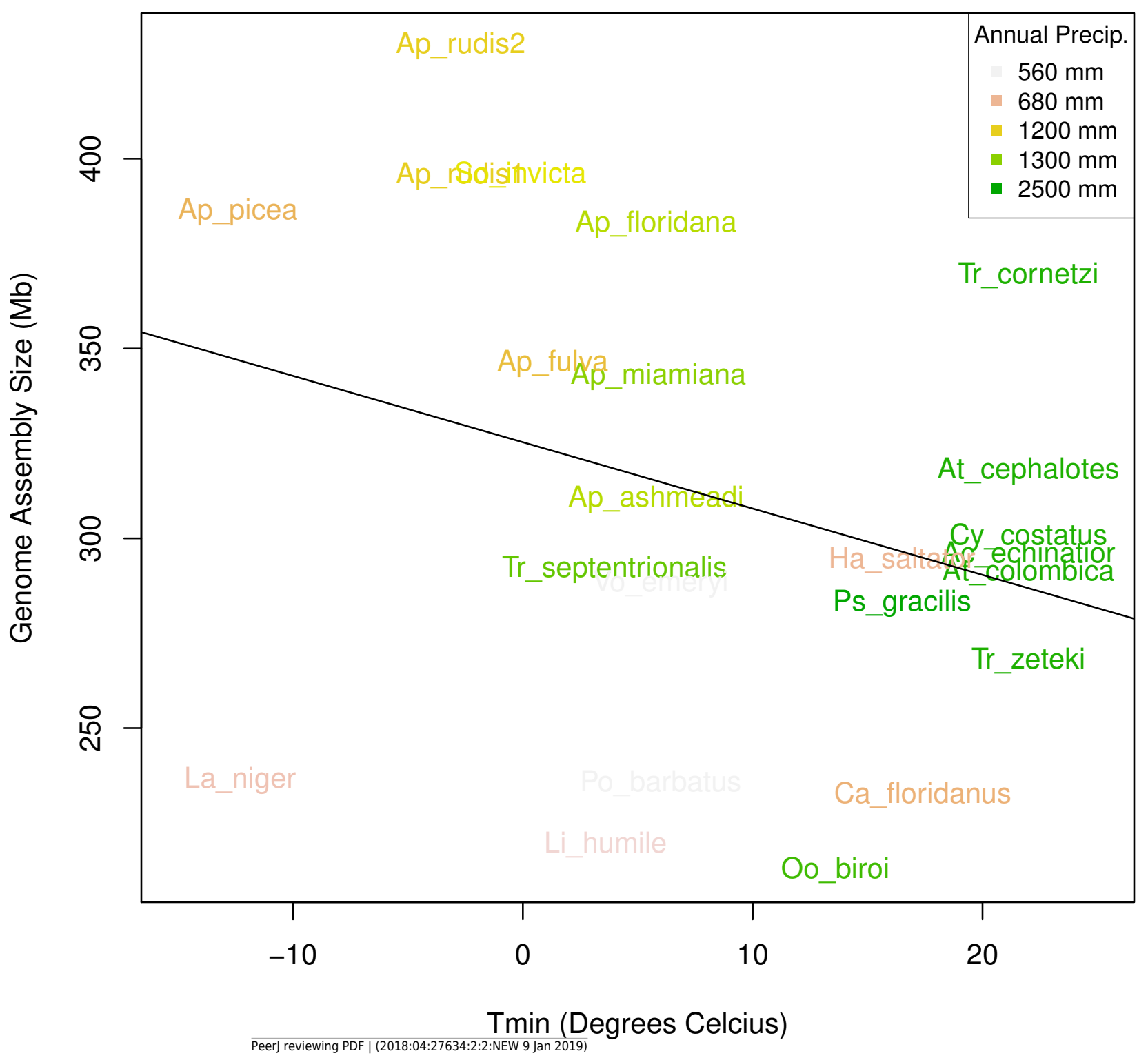

